\title{
Soil Amplification in Low-to-Moderate Seismic Regions
}

1. Ryan D. Hoult, Corresponding Author. PhD Candidate, Department of Infrastructure Engineering, University of Melbourne, Parkville, 3010, Australia.

Email: rhoult@student.unimelb.edu.au

$\mathrm{Ph}:+61401955374$

Postal: 25 College Crescent, Parkville, VIC, 3052

2. Elisa Lumantarna, Lecturer, Department of Infrastructure Engineering, University of Melbourne, Parkville, 3010, Australia. Email: elu@unimelb.edu.au

3. Helen M. Goldsworthy, Associate Professor, Department of Infrastructure Engineering, University of Melbourne, Parkville, 3010, Australia. Email: helenmg@unimelb.edu.au

\section{Introduction}

Australia resides completely within the Indo-Australian plate, a thin and significantly fractured shell that is slowly moving north at $10 \mathrm{~cm}$ per year (Wilson et al., 2008). Earthquakes in Australia are commonly known as intra-plate events, since they occur away from the plate boundary. Although these events have an occurrence rate much lower than inter-plate events, Australia is known to be one of the most active intra-plate regions in the world. On average, Australia experiences two earthquakes that are over local magnitude $\left(M_{L}\right) 5$ per year, but also has the potential for larger, more damaging earthquakes of $M_{L} 6$ or higher once every three to five years, which evidently could occur anywhere within the country (Leonard, 2008).

Although recognition of earthquake hazard in Australia is generally low within the general public, mainly due to the moderate and large earthquake events occurring away from populated centres (Wilson et al., 2008), there have been some past incidents which have resulted in widespread damage. The $M_{L} 5.6$ Newcastle earthquake in 1989 caused the largest earthquake damage in Australian seismic history, killing 13 people, injuring at least 160 and making around 1000 people homeless (Walker, 2011). The earthquake caused losses of around $\$ 3.2$ billion calculated on the basis of the same event occurring in 2013 (Goldsworthy, 2012). A strong correlation has been observed between the areas of maximum damage around Newcastle from the event and the geographical extent of Quaternary sediments (Jones et al., 1996). The event is hence considered by some researchers to be one of many examples where site amplification has played a major role in the destruction caused by moderate earthquakes (Anbazhagan et al., 2013). However, recent research has determined that rather than the presumed correlation between the site class and damage, the observed damage distribution is controlled mainly by the buildings' age and construction type (McPherson \& Hall, 2013). McPherson and Hall (2013) show that much of the recorded building damage in Newcastle is mapped onto the soft or deep soil class ('Holocene alluvium materials'); however, the area in which these sediments are found largely coincides with those in which there 

are many older unreinforced masonry buildings. If the age of the buildings and the construction type are taken into account, the proportion of damage on the softer site class ('Fine-grained alluvial/estuarine deposits') is much lower than expected, whereas the number of badly damaged structures on rock sites is higher than expected. Moreover, the results of nonlinear site response analyses conducted by Chandler et al. (1991) using borehole data from the Newcastle region suggested that the deeper, softer sites were unlikely to have caused any substantial amplification effects with regards to the 1989 earthquake. Although it was found that the shallow and soft soil sites appeared to amplify the seismic ground motions in the short period range, Chandler et al. (1991) concluded that the potential correlation of the building damage and regions of deep alluvial soil deposits around Newcastle was not corroborated by the observed damage distribution nor by the nonlinear analytical results. The results from the study presented in this paper will show that a different explanation is possible when assessing the damage pattern observed on sites with different soil conditions.

Recent research has indicated that the earthquake amplification at the surface of a site is not only dependent on the stiffness of the underlying soil but also on the intensity of the bedrock ground motions (Dhakal et al., 2013; Walling et al., 2008). An example of the dependence on the stiffness of the underlying soil is given in Dhakal et al. (2013) who showed that rock class deposits 'produced larger amplification at short periods that are greater than the short-period response of soils'. This is in direct contrast to the design spectral shapes given in NZS 1170.5 (Standards Association NZ, 2004) and similarly given in AS 1170.4:2007 (Standards Australia, 2007). The results from Dhakal et al. (2013) and Walling et al. (2008) indicated that in general, the lower the intensity of the bedrock motion the greater the amplification of the response spectrum. Dhakal et al. (2013) also showed that the output to input ratio of the seismic ground motions from the bedrock to the surface of a site decreased as the intensity of the earthquake increased. This was observed to be prominent in the short period range for rock sites, whereas the output to input ratio atop of the "soft soil" sites was found to be more consistent across all periods and had greater variance with the intensity of the earthquake.

The views expressed by Dhakal et al. (2013) about the dependence of the amplification on the site conditions are consistent with a further observation from the Christchurch ( $\mathrm{ChCh})$ earthquake of February $22^{\text {nd }} 2011$. The moment magnitude $\left(M_{w}\right) 6.2$ event was captured by two seismometer recording stations within a kilometre

61 distance from one another. The two stations, LPCC and LPOC, were on sites that had different soil conditions; the LPCC station recorded the event on 'engineering bedrock' with a source-to-site distance $\left(R_{\text {rup }}\right)$ of $7.1 \mathrm{~km}$, whereas the LPOC station had a $R_{r u p}$ of $6.6 \mathrm{~km}$ and was located on a site with a shallow soil that primarily 
contained silts and clays (Bradley \& Cubrinovski, 2011). The spectral acceleration results from the ChCh event recorded at these two stations are given in Figure 1. The spectral acceleration in the short period range $(0-0.5 \mathrm{~s})$ has clearly been decreased for the soft soil (LPOC) in comparison to the rock site (LPCC).

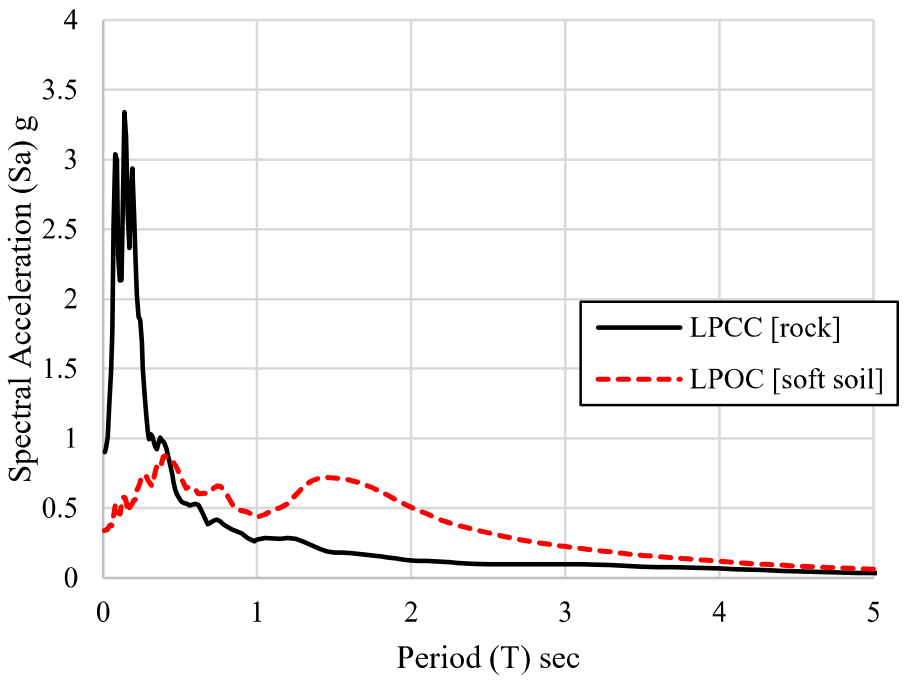

Figure 1 Acceleration response spectra from the Christchurch earthquake on rock and soft soil

The observations of the spectral acceleration from the Christchurch earthquake event as captured by the two seismometers in Figure 1 do not reflect the shape of the design spectra specified in some current earthquake loading provisions, including the Australian Standards Earthquake Actions AS 1170.4:2007.

This paper presents a study that has been undertaken to investigate the site amplification of different site subsoil classes with varying depths subjected to a range of earthquake intensities. The bedrock has been subjected to a suite of ground motions that represent intensities consistent with rare to very rare events in low-to-moderate seismic regions such as Australia, with peak ground accelerations $(P G A)$ ranging from $0.1 \mathrm{~g}$ to $0.3 \mathrm{~g}$. The results of the acceleration response at the surface of the soil site are normalised so that they can be directly compared with the Spectral Shape Factors in the current AS 1170.4:2007. Also, taking advantage of improvements that have been made in the latest strong ground motion database from the Pacific Earthquake Engineering Research Center (PEER, 2013), in which a larger dataset of ground motion records, and importantly the estimated shear wave velocities at the sites where they were recorded, have been provided, the results from this study have been compared directly to those from earthquake records for different site conditions.

\section{Spectral Shape Factors in Australia}


It has widely been accepted in the engineering community that the seismic motions at the surface of a soil deposit can be significantly different to the seismic motions of the underlying bedrock. The general view, which is consistent with some of the international provisions for earthquake actions (Eurocode 8, 2004; ICC, 2009; Standards Association NZ, 2004; Standards Australia, 2007), is that the harder the rock the lower the amplification of ground motion at the surface compared with the bedrock motion. Conversely, the softer the soil deposit the greater the amplification of the ground motions at the surface of the layer.

The first spectral and site response factors adopted by the Standards (ICBO, 1994; Standards Australia, 1993) were based on the study by Seed \& Idriss (1982), which identified three different primary soil conditions that were subsequently used in these provisions with two classes for rock. A revision of the spectral shapes, primarily based on the research by Martin \& Dobry (1994), Borcherdt (1994) and Crouse \& McGuire (1996), led to the adoption of new scaling factors to define the spectral shapes (or response spectra) in the UBC97 (ICBO, 1997), IBC2000 (ICC, 2000). The scaling factors were also adopted in the Australian Standards for Earthquake Actions AS 1170.4:2007, where the surface amplification of the bedrock seismic motions for each of the soil classes is represented by a spectral shape factor $\left(C_{h}(T)\right)$, shown in Figure 2. The definitions of the soil classes in Figure 2, from $A_{e}$ to $E_{e}$, will be discussed later in Section 3.

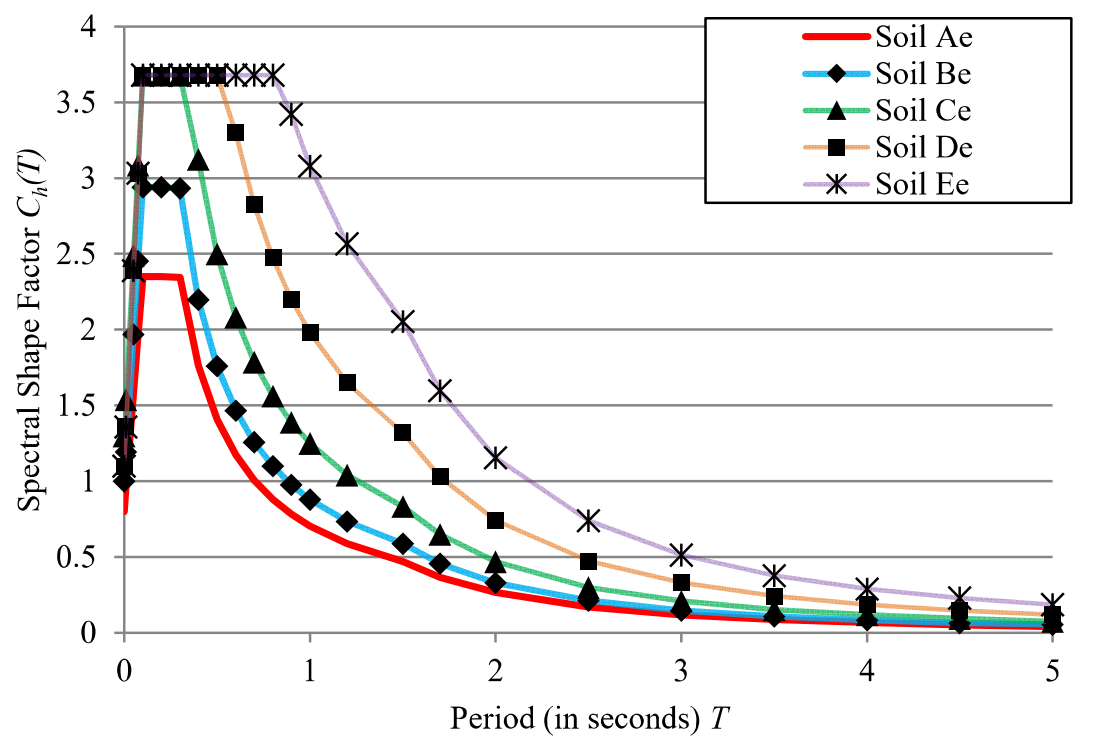

100 The $C_{h}(T)$ are calculated, as shown in Equation 1, as the ratio of the spectral acceleration value, $S_{\mathrm{a}}$, for each of 101 the soil classes, for the corresponding period, $T$, to the $P G A$ on rock (defined as the $P G A$ on site sub-soil class 
$102 B_{e}$, i.e. $\left.P G A_{B}\right)$. Figure 2 illustrates the response spectra shape for the different soil site classes, from Strong

103 Rock $\left(A_{e}\right)$ to Very Soft Soil $\left(E_{e}\right)$; for a given period, $T, C_{h}(T)$ generally increases as the "softness" of the site

104 increases. The Spectral Shape Factor $\left(C_{h}(T)\right)$ is an important parameter that is used in determining the

105 horizontal static shear force when designing a structure for earthquake loads using the conventional equivalent

106 static analysis procedure in Section 6 of AS 1170.4:2007.

$C_{h}(T)=S_{a}(T) / P G A_{B}$

107 Crouse \& McGuire (1996) used a large number of strong motion events in California that were recorded from

1081933 through to 1992 . The database included a large number of strike-slip earthquake events, and yet the strike-

109 slip mechanism is not usually observed in Australia. Moreover, the values of $P G A$ corresponding to the events

110 used in the study are often outside the limits of what would normally be considered to correspond to a rare to

111 very rare event in Australia, with $P G A$ of up to $0.5 \mathrm{~g}$ being used. For a 500 -year return period event, the Hazard

112 Factor $(Z)$ given by AS 1170.4:2007 for most capital cities in Australia ranges from 0.08g to 0.1g, with higher

113 values of $0.13 \mathrm{~g}$ and $0.20 \mathrm{~g}$ being used for Tennant Creek and Meckering, respectively. In accordance with AS

114 1170.4:2007, multiplying these Hazard Factors by a Probability Factor $\left(k_{p}\right)$ of 1.8 gives the Hazard Factor that

115 represents a very rare earthquake event (2500-year return period). Hence for a 2500-year return period event the

116 Hazard Factor varies from $0.144 \mathrm{~g}$ to $0.36 \mathrm{~g}$. It is possible that the high $P G A$ events used in the study by Crouse

$117 \&$ McGuire (1996) have given a false representation of the level of site amplification; this would be true if

118 higher intensity events tend to have reduced amplification as found by Dhakal et al. (2013) and Walling et al.

119 (2008). Crouse \& McGuire (1996) acknowledged the need to update their findings as new data became

120 available. Given that the available strong ground motion database has been improved considerably in the last

121 two decades, there is a compelling case to proceed with this update.

122 Evidence of larger site amplification from lower intensity events found by Dhakal et al. (2013) and Walling et

123 al. (2008) suggests that the methodology used to derive the amplification factors in AS 1170.4:2007 needs to be

124 updated. The methodology, site profiles and ground motion selection used in this study are explained further in

125 Section 3.

126 3. Site Amplification Investigation: Methodology 
128 SHAKE2000 (Ordonez, 2013) uses the equivalent linear method to simulate the acceleration response at the

129 surface of the different soil layers and to determine the maximum strains induced within these soil columns.

130 The equivalent linear analysis was originally developed by Schnabel et al. (1972) and uses an iterative process

131 to calculate the linear variation of the shear modulus and damping of the soil layers with magnitude of shear

132 strain. SHAKE2000 applies the seismic ground motions at the junction of the soil column and bedrock to

133 ultimately predict the response at the surface. For rock sites the material properties proposed by Schnabel

134 (1973) were used in this study, with a specific weight $(\gamma)$ of $23 \mathrm{kN} / \mathrm{m}^{3}$. Average damping ratios and shear

135 modulus degradation curves for a sandy material (Seed \& Idriss, 1970) with a $\gamma$ of $19 \mathrm{kN} / \mathrm{m}^{3}$ were used to

136 represent the dynamic soil properties of sites $C_{e}, D_{e}$ and $E_{e}$. These material properties have been used in

137 previous seismic response studies in Australia (Lam \& Wilson, 1999; Lam \& Wilson, 2008; So et al., 2015).

138 The results from the equivalent linear analyses will generally only be deemed acceptable if strains are less than

$1390.5 \%$. The reason for this limitation being imposed on the strains is that it has been reported in previous research

140 by Beresnev and Wen (1996) that there can be discrepancies between the results from the equivalent linear

141 approach, which is adopted by SHAKE2000 (Ordonez, 2013), and the more realistic "true non-linear approach".

142 However, Papaspiliou et al. (2012) have determined that the results obtained from the equivalent linear

143 approach are reasonable for soils that have expected maximum strains not exceeding $1 \%$ and for "sandy sites"

144 with maximum strains not exceeding $0.5 \%$.

\section{$145 \quad 3.2$ Soil profiles}

146 The site class definitions in AS 1170.4:2007 are differentiated by the average shear-wave velocity $\left(V_{s}\right)$ through

147 either the material in the top $30 \mathrm{~m}\left(V_{s 30}\right)$ or top $10 \mathrm{~m}\left(V_{s 10}\right)$, or by the low-amplitude natural site period $\left(T_{n}\right)$, as

148 indicated in Table 1. The indicated $T_{n}$ value, with known depth of the soil profile that is being modelled, can be

149 used to calculate the appropriate shear-wave velocity limits for soils $C_{e}$ and $D_{e}$ using Equation 2, as it is defined

150 as 'four times the shear-wave travel time from the surface to rock' (Standards Australia, 2007). It should be

151 noted that other soil classification systems internationally have a much higher minimum $V_{s 30}$ value for soil class

$152 B_{e}$ representing 'firm to hard rock', including the National Earthquake Hazard Reduction Program (NEHRP)

153 Site Classes, where the Simplified Site Classes specify $V_{s 30}$ values between $760 \mathrm{~m} / \mathrm{s}$ and $1500 \mathrm{~m} / \mathrm{s}$ for site class

154 B (Building Seismic Safety Council, 2009).

$T_{n}=4 H / V_{s 30}$

155 where $H$ is the depth of the soil. 


\begin{tabular}{ccccc}
\hline Site Sub-Soil Class & Definition & $V_{s 30}(\mathrm{~m} / \mathrm{s})$ & $V_{s 10}(\mathrm{~m} / \mathrm{s})$ & $T_{n}(\mathrm{sec})$ \\
\hline$A_{e}$ & Strong Rock & $>1500$ & - & - \\
$B_{e}$ & Rock & $>360$ & - & - \\
$C_{e}$ & Shallow soil & - & - & $<0.6$ \\
$D_{e}$ & Deep or Soft soil & - & - & $>0.6$ \\
$E_{e}$ & Very soft soil & - & $<150$ & - \\
\hline
\end{tabular}

158 Table 2 contains the information used in this study for each of the five site sub-soil classes; the chosen soil

159 profiles have constant shear-wave velocity and changing soil depth. Previous investigations by the authors

160 (Hoult et al., 2013) and Dhakal et al. (2013) have indicated that using a single layer with constant shear wave

161 velocity can correlate well with the results of a soil profile of multiple layers which has an equivalent average

162 shear wave velocity. Nevertheless, it is acknowledged that this assumption may not be valid for all sites and this

163 will need to be investigated in future studies. Due to the provisional restriction on maximum depth for the

164 'Shallow Soil Site' class $C_{e}$, a maximum depth of only 60 meters will be used in the analysis. It is also worth

165 noting that for this soil class, due to the constraints on the site period that define the class (i.e. $T_{n}<0.6 \mathrm{sec}$ ), the

166 shear-wave velocity will be altered depending on the soil depth $(H)$, as indicated in Table 2.

Table 2 The different soil profiles implemented in SHAKE2000 (Ordonez, 2013)

\begin{tabular}{ccccc}
\hline Site Sub-Soil Class & $V_{s}(\mathrm{~m} / \mathrm{s})$ & $H(\mathrm{~m})$ & $T_{n}(\mathrm{sec})$ & Material \\
\hline$A_{e}$ & 1500 & $30 / 60 / 90 / 150$ & $0.08 / 0.16 / 0.24 / 0.40$ & Rock (Schnabel, 1973) \\
$B_{e}$ & 760 & $30 / 60 / 90 / 150$ & $0.16 / 0.32 / 0.47 / 0.79$ & Rock (Schnabel, 1973) \\
$C_{e}$ & $250 / 450$ & $30 / 60$ & $0.48 / 0.53$ & Sand Avg. (Seed \& Idriss, 1970) \\
$D_{e}$ & 180 & $30 / 60 / 90 / 150$ & $0.67 / 1.33 / 2.00 / 3.33$ & Sand Avg. (Seed \& Idriss, 1970)
\end{tabular}


169 There is some evidence from Melbourne to support the chosen bedrock shear-wave velocity of $1500 \mathrm{~m} / \mathrm{s}$. Asten

170 et al. (2005) surveyed the shear-wave velocity at several locations around Melbourne to find that the Melbourne

171 Mudstone, which is generally the type of rock that the bedrock is made of, was in the range of $1800-2000 \mathrm{~m} / \mathrm{s}$,

172 while at some other sites it was softer (corresponding to a lower $V_{s}$ value of $1500 \mathrm{~m} / \mathrm{s}$ ). Moreover, Anbazhagan

173 et al. (2013) have shown that there are no significant differences in the response spectra amplification factors

174 when the bedrock shear wave velocity is between $1385 \mathrm{~m} / \mathrm{s}$ and $1868 \mathrm{~m} / \mathrm{s}$.

\subsection{Intensities and Ground Motion Selection}

Peak ground accelerations $(P G A \mathrm{~s})$ have been chosen to appropriately represent the ground motion intensities for rare and very rare earthquake events that can occur in the low-to-moderate seismic region of Australia. As discussed previously in Section 2, the PGA or Hazard Factor (Z) given by AS 1170.4:2007 for a 500-year and 2500-year return period event in Australia can range from around $0.08 \mathrm{~g}$ to $0.36 \mathrm{~g}$ respectively. Therefore, it was decided to use $P G A$ values of $0.1 \mathrm{~g}, 0.2 \mathrm{~g}$ and $0.3 \mathrm{~g}$ in this study. The soil class $A_{e}$ spectra derived from AS 1170.4:2007 were adopted as the 'target spectra' and used to determine suitable ground motions for input into SHAKE2000.

Although some earthquake data has been captured in recent events in Australia (Hoult et al., 2014), there is still a paucity of data that represents the larger events of interest (e.g. $M_{w}$ in the range 5 to 7.5 ). Moreover, virtually no information exists for the site conditions at the locations of the various seismometers that have captured these past events. Therefore, seismic ground motions that have been captured internationally will be used; ones that possess similar earthquake characteristics to those typically observed in Australia.

The ground motions were selected from (PEER) 2013 based on a range of different magnitudes and at limiting distances to obtain acceleration-time histories with a mixture of frequency content. The ground motions were selected under the following criteria:

- Moment magnitude $\left(M_{w}\right)$ range of 4 to 7

- Reverse, Reverse-Oblique and Normal fault types

- Joyner-Boore distance $\left(R_{j b}\right)$ range of $10 \mathrm{~km}$ to $150 \mathrm{~km}$

- $V_{s 30}$ range of $600 \mathrm{~m} / \mathrm{s}$ to $1800 \mathrm{~m} / \mathrm{s}$ 
195 Fifty-eight ground motion records from the PEER (2013) ground motion database conformed to these criteria.

196 The earthquake records were further limited to twenty-nine ground motions (with two horizontal recordings, 58

197 acceleration-time history files) such that the majority of the records were reverse fault type mechanisms, which

198 is the most commonly observed focal mechanism for Australian earthquake events (Brown \& Gibson, 2004).

199 These twenty-nine ground motions were subsequently scaled to closely envelope the spectrum from the current

200 AS 1170.4:2007 on strong rock (class $A_{e}$ ). PEER calculates an appropriate, single magnitude factor for each

201 corresponding record by 'minimising the mean squared error between the spectrum of the scaled records and the

202 target spectrum' (PEER, 2010). The selected ground motions, and the scaling required for each to ensure that

203 they collectively enveloped the soil class $A_{e}$ spectra (for $Z=0.1 \mathrm{~g}, 0.2 \mathrm{~g}$ and $0.3 \mathrm{~g}$ ) closely, are given in Table A1 in

204 the Appendix. The majority of the records have been scaled to within a quarter to four times the original

205 amplitude. However, some of the other scaling factors are high, typically corresponding to a moderate

206 magnitude event and/or a large epicentral distance. However, the focus for this study was to use as many real

207 acceleration time-histories as possible, ones that conformed to the particular criteria, in order to model the

208 bedrock ground motions typical of large Australian seismic events. These types of earthquake scenarios, with

209 respect to the magnitude and distance combination, and corresponding frequency content are what are typically

210 expected for Australian earthquakes (Lumantarna et al., 2012). The accelerations obtained from PEER are

211 assumed to be outcrop motions, and recorded at the top of an outcrop with the same rigidity as the underlying

212 bedrock.

213 Site analyses were performed using the program SHAKE2000 with the 58 scaled acceleration-time history files

214 as the input motions and soil parameters that are varied in accordance with Table 2. The results of the

215 maximum shear strains experienced in the soil columns for the range of seismic intensities are given in Section

2164 to verify the use the equivalent linear analysis. The Spectral Shape Factors $C_{h}(T)$ can then be calculated for

217 each of the soil profiles (Equation 1). The median of the site response from the 58 acceleration-time histories

218 used for each of the soil profiles (and seismic hazard intensities) are normalised to the results for the $P G A_{B}$

219 (class $B_{e}$ ). In Section 5, the results for the spectral shape factors are given and they are then compared to those

220 in the current Australian Standards (Standards Australia, 2007).

\section{Maximum Shear Strains}

222 Figure 3(a-d) shows the SHAKE2000 results for the maximum strains experienced in each of the different soils, 223 including all of the intensities and depths that have been investigated. The results show that for the majority of 
cases the mean maximum strain is less than $0.5 \%$. In only one case does the strain slightly exceed $0.5 \%$, i.e. when the depth to bedrock of soil $E_{e}$ is $30 \mathrm{~m}$ and it is subjected to a bedrock hazard intensity of $0.3 \mathrm{~g}$. As the depth to bedrock increases the results show that the maximum strains experienced by the soils decrease and they are all less than $0.5 \%$.

To further support these results, the $60 \mathrm{~m}$ soil $E_{e}$ profiles was investigated using a nonlinear analysis with the same ground motions (Table A1, Appendix) scaled for an intensity ( $Z$ value) of $0.3 \mathrm{~g}$. This profile represented a conservative case in comparison with the majority of the other profiles, it produced one of the highest estimates of the mean maximum strain values using the equivalent linear method (as shown in Figure 3b). Onedimensional equivalent linear and nonlinear site response analyses were conducted using DEEPSOIL (Hashash et al., 2016), which has been used in previous research investigating site response (Hashash et al., 2015; Bolisetti et al., 2014; Choudhurry et al., 2009; Groholski et al., 2016). DEEPSOIL treats the soil column as a multi-degree-of-freedom lumped mass model. A stiffness matrix is recalculated at each time increment, which is calculated based upon the mass lumped between the junctions of the soil layers. The recommended frequency independent damping matrix type was used for the nonlinear analyses and the extended hyperbolic PressureDependent Modified Kondner Zelesko (MKZ) formulation proposed by Matasovic (1993) was used for the nonlinear backbone. The $60 \mathrm{~m}$ sand layer was subdivided into four $15 \mathrm{~m}$-thick layers from the surface to a depth of $60 \mathrm{~m}$. The mean damping ratios, shear modulus degradation and strain curves from Seed \& Idriss (1970) were used in DEEPSOIL for the sand layers, and these were identical to those used in SHAKE2000. A modulus reduction and damping curve fitting procedure was adopted to find the values of the parameters of the sand material needed for nonlinear analyses. The resulting maximum strain values from DEEPSOIL, using the mean of the result from the 58 scaled ground motions, are illustrated as a function of the soil depth in Figure 4. Superimposed on these figures are the results from SHAKE2000. The equivalent linear (EL) results from DEEPSOIL correlate well with the results from SHAKE2000, as expected. However, the nonlinear (NL) results from DEEPSOIL differ slightly, with lower strains estimated at shallower depths and higher strains at larger depths, when compared with the equivalent linear results. However, the maximum difference between the EL and NL results are small, with a maximum strain value of approximately $0.5 \%$ estimated from the NL method. Hence, the equivalent linear method has been shown to give reasonable predictions of the mean maximum strains induced in the soil. Except for the extreme case of site class $E_{e}$ and a $0.3 \mathrm{~g} Z$ value, the mean maximum value of the strain obtained using the equivalent linear method has been shown to be below the required limit; 

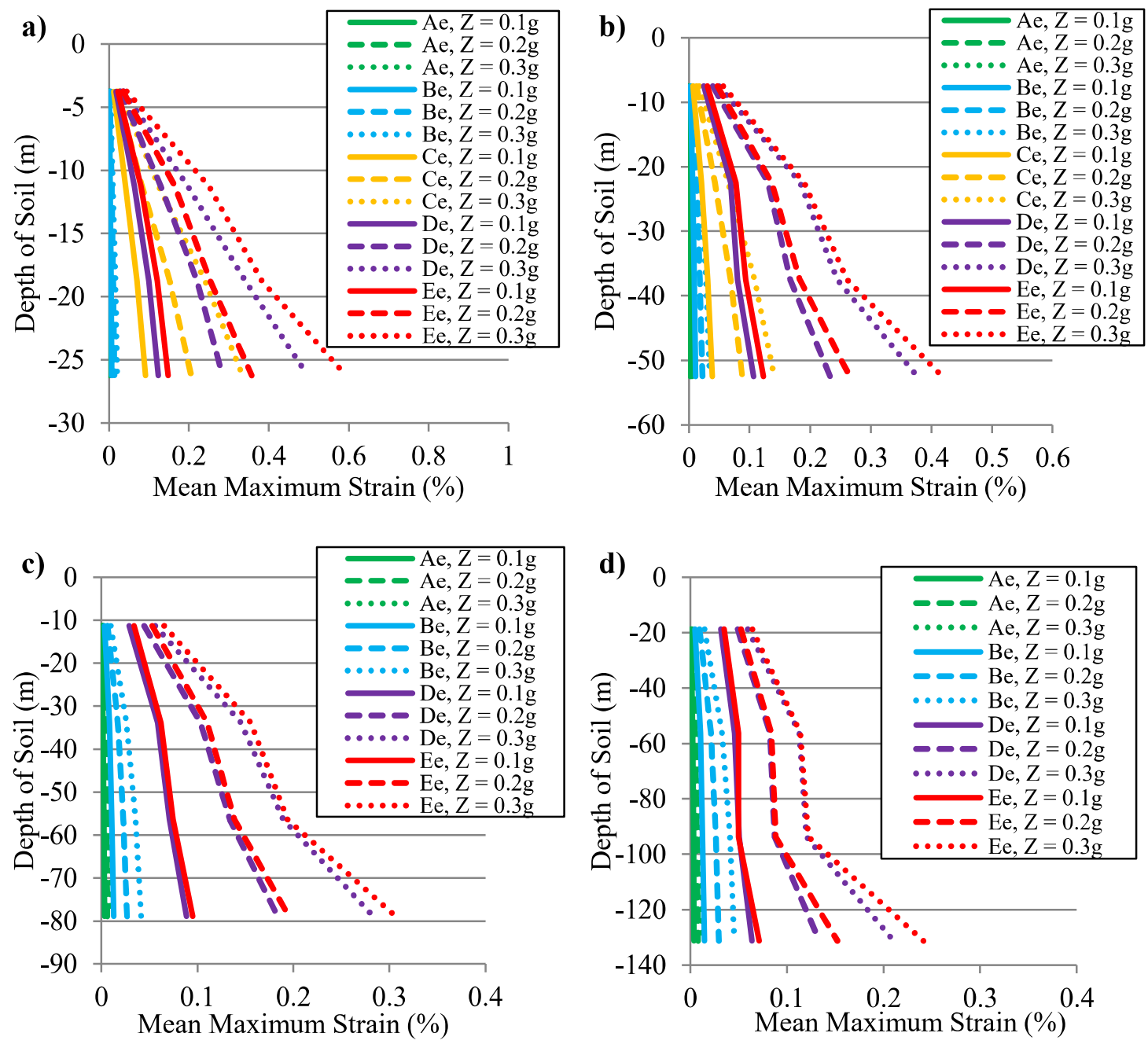

Figure 3(a-d) The maximum strains (\%) experienced in the different soil profiles and under different seismic

intensities for depths of (a) $30 \mathrm{~m}$ (b) $60 \mathrm{~m}$ (c) $90 \mathrm{~m}$ and (d) $150 \mathrm{~m}$ 


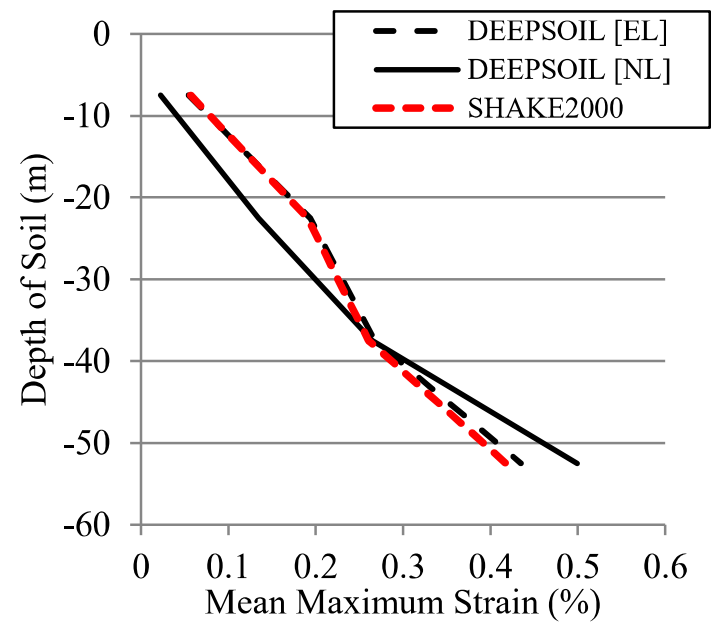

Figure 4 Maximum strains for soil $E_{e}$ with a depth of $60 \mathrm{~m}$

\section{Spectral Shape Factors $C_{h}(T)$}

For each soil parameter, the median acceleration response was found and then normalised using Equation 1 to obtain the spectral shape factors. The spectral shape factors are presented in Figure 5(a-e) for soil class $A_{e}$ through to $E_{e}$ respectively. Superimposed on these figures are the AS 1170.4:2007 spectral shape factors $\left(C_{h}(T)\right)$ corresponding to the given site sub-soil class.

Not surprisingly, the median results from SHAKE2000 for soil class $A_{e}$ in Figure 5(a) envelope the AS 1170.4:2007 spectral shape factors reasonably well after a period of around 0.3s. This is because the geometric mean of the factored acceleration-time histories are targeted to match closely to this spectrum (for three different $Z$ values). Although the spectral shape factors are not closely correlated in the low period range (0$0.3 \mathrm{~s}$ ) it should be noted that most building periods are beyond this range. Similar to soil class $A_{e}$, the results for soil class $B_{e}$ in Figure 5(b) are not dependent on seismic intensity. Lower amplification is expected for higher intensities if the site experiences greater non-linear behaviour due to higher levels of site degradation during the more intense earthquakes. Site resonance can also be observed in the results for site class $B_{e}$, with the second "peaks" of the acceleration response occurring close to the site periods (obtained using Equation 2) of 0.16s, $0.31 \mathrm{~s}, 0.47 \mathrm{~s}$ and $0.79 \mathrm{~s}$ for the profiles of depths $30 \mathrm{~m}, 60 \mathrm{~m}, 90 \mathrm{~m}$ and $150 \mathrm{~m}$ respectively. More pronounced resonance effects, which would result in larger spectral shape factor results than what are predicted by the current AS 1170.4:2007, are likely to occur if even lower $V_{s}$ values are used for soft rock, such as the $360 \mathrm{~m} / \mathrm{s}$ 
that the provision allows, and this should be the subject of further studies. Large resonance effects are clearly seen in Figure 5(c) for the sandy material used to represent soil class $C_{e}$. Not only is the "peak" due to site resonance (which occurs at a period that approximately matches the site period found using Equation 2) higher than what is stipulated by AS 1170.4:2007, but the magnitude of the amplification is observed to be dependent on the intensity of the earthquake. The intensity dependent (de)amplification can also be observed for soil classes $D_{e}$ and $E_{e}$ in Figures 5(d) and (e) respectively. However, for classes $D_{e}$ and $E_{e}$, the spectral factors from SHAKE2000 are predicted to be much lower than what is stipulated by the current AS 1170.4:2007, particularly for the lower period range.

These results give another explanation for the structural damage observations in Newcastle discussed in Section 1; it is possible that the low to moderate intensity earthquake event caused a large amplification at the surface of the acceleration response of stiff structures on rock sites, whereas the amplification was relatively low for these structures on the soft and deep soil sites that are prevalent in the Newcastle area.
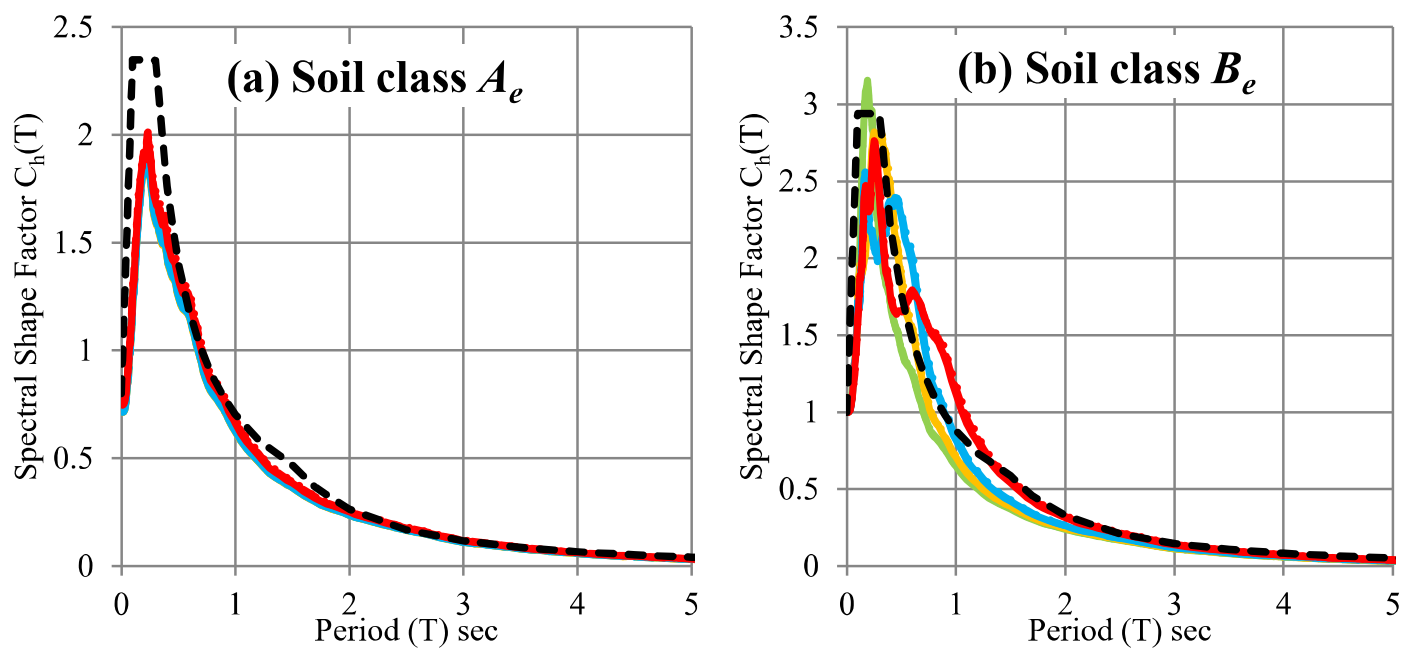

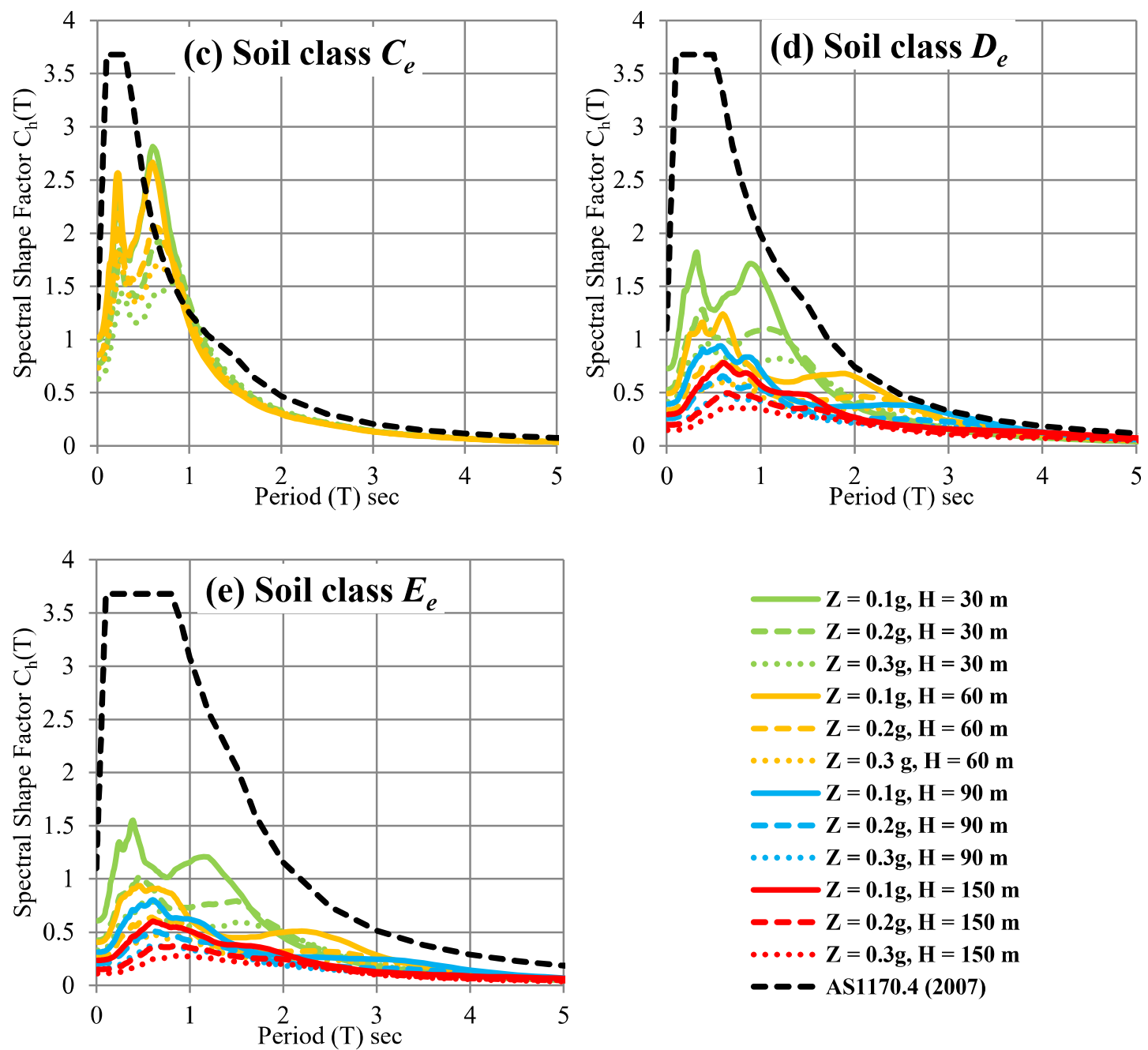

Figure 5(a-e) Spectral Shape Factor results from SHAKE2000 for soil classes $A_{e}$ through to $E_{e}$

It is possible that the lower spectral shape factors predicted by SHAKE2000 for soil classes $C_{e}, D_{e}$ and $E_{e}$ are due to the assumption of the material used (sand) in representing these sites. Therefore, equivalent linear analyses were performed in SHAKE2000 on these soil classes using a different material to represent a clay site.

The clay material was modelled using the damping ratios and shear modulus degradation curves from Vucetic \& Dobry (1991), which are commonly used to model the clay behaviour in site response studies using SHAKE2000 (Chatterjee et al., 2015; Jakka et al., 2014; Kamatchi et al., 2010). A specific weight $(\gamma)$ of $18 \mathrm{kN} / \mathrm{m}^{3}$ and a moderate to high value of the plasticity index $(30 \%)$ were used to provide a conservative response. The clay profiles had the corresponding depths and shear wave velocity as given for the sand sites in Table 2 to conform with the classification of soils given in AS 1170.4:2007. The results from SHAKE2000 using the clay material are given in Figure 6, with the superimposed $C_{h}(T)$ derived from AS 1170.4:2007. It is clear that, for the given depths and intensities investigated here, the clay material with a high plasticity index has 
the potential to cause larger amplification in comparison to results using the sand material (Figure 5).

Nevertheless, the results in Figure 6 clearly show an intensity dependent amplification of the bedrock seismic ground motions at the surface. Interestingly, one of the depth and shear wave velocity combinations $(H=60 \mathrm{~m}$, $V_{s}=450 \mathrm{~m} / \mathrm{s}$ ) used for the soil class $C_{e}$ profiles resulted in a much larger amplification in the short period range for the lowest seismic intensity used $(Z=0.1 \mathrm{~g})$ in comparison to the spectrum derived from the AS 1170.4:2007 in Figure 6(a). Moreover, (de)amplification is still observed in the low period range for soil classes $D_{e}$ and $E_{e}$ in Figure 6(b) and (c), with the exception of the lowest intensity and shallowest soil profile for $D_{e}(Z=0.1 \mathrm{~g}, H=$ $30 \mathrm{~m})$. Further research is still needed to clarify the soil amplification response of site classes $C_{e}, D_{e}$ and $E_{e}$, in particular by using different materials with different properties (e.g. range of plasticity indices).
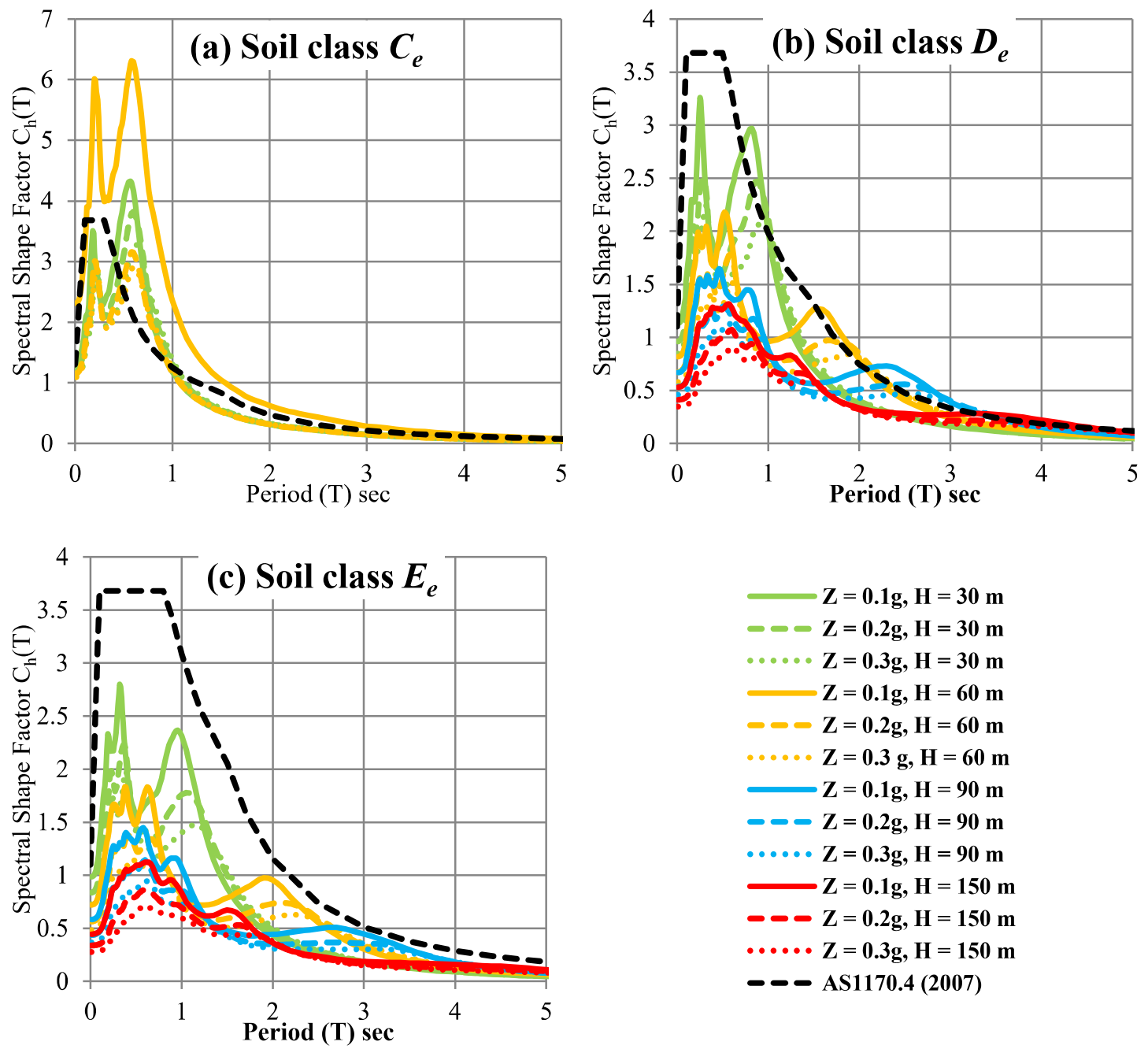


\section{Modified Spectral Shape Factors $C_{h}$ '(T)}

313 A different method of normalisation is used in this section to allow a comparison to be made between the

314 amplification of the response from the ground motion at the surface to the structure (which is one component of

315 the spectral shape factors obtained in Section 5), with those from a vast set of actual records for different site

316 conditions from the PEER (2013) ground motion database. For each of the PEER ground motions the $P G A$ at

317 the surface is known, however the ground motion at the bedrock is not known; hence a different method of

318 normalisation was needed. The values of $V_{s 30}$ at the site of each recorded earthquake that have been provided in

319 the PEER database are used to categorise the acccelerograms into their soil classifications in accordance with

320 AS 1170.4:2007. The "modified" spectral shape factor $\left(C_{h}\right.$ ' $\left.(T)\right)$ can be calculated with Equation 3, which

321 normalises the acceleration response spectra associated with a particular unscaled surface ground motion record

322 by dividing by the intensity of the surface ground motion, or $P G A$. The "modified" spectral shape factor

$323\left(C_{h}^{\prime}(T)\right)$ was defined by Dhakal et al. (2013) and is used, among other parameters, in an expression they

324 proposed to calculate the elastic site hazard spectrum. This factor represents the amplification of the response

325 acceleration due to the structural response to the surface ground motion. The median of the $C_{h}$ ' $(T)$ for all of the

326 records associated with each soil class has been calculated throughout the period range. For soil sites in

327 particular, this factor is expected to be sensitive to resonance effects for structures that have natural periods

328 close to or at the site period.

329 The soil spectra from the PEER database, normalised according to Equation 3, are compared with the median results of the SHAKE2000 analyses in Section 5 for each soil class. In order for a direct comparison to be made,

331 the results from Section 5 have been adjusted following the same normalisation procedure. It should be noted that the ground motions obtained from PEER for this part of the study satisfy the criteria introduced in Section

3332.3 with regards to the range of magnitudes and distances, and the faulting mechanisms. Table 3 lists the

334 number of recorded ground motions from PEER that were used in each site sub-soil class in the comparisons

335 with the analytical results from SHAKE2000.

$$
C_{h}^{\prime}(T)=\frac{S_{a}(T)}{P G A}
$$

Table 3 Number of earthquake acceleration records used for different site classes from the PEER (2013) Database 


\begin{tabular}{ccc}
\hline Site Sub-Soil Class & $\mathrm{V}_{\mathrm{s} 30}(\mathrm{~m} / \mathrm{s})$ & No. of Acceleration-time Histories \\
\hline$A_{e}$ & $>1500$ & 12 \\
$B_{e}$ & $360-1500$ & 272 \\
$C_{e}$ & $200-360$ & 110 \\
$D_{e}$ & $170-200$ & 60 \\
$E_{e}$ & $<170$ & 54 \\
\hline
\end{tabular}

340 Figures 7(a-e) present the median $C_{h}^{\prime}(T)$ results of the PEER (2013) ground motion database for unscaled

341 (normalised) acceleration spectra for soil classes $A_{e}$ through to $E_{e}$ respectively. The figures also include the

342 median results from SHAKE2000 with a normalisation following Equation 3. The figures show that the

343 normalised results obtained using the PEER (2013) records correlate reasonably close to the normalised results

344 from SHAKE2000. The unscaled records for Class $A_{e}$ in Table 3 are a subset of the records used in Table A1 in

345 the Appendix. Nevertheless, as shown in Figure 7(a), the two normalised spectra for soil class $A_{e}$ match very

346 closely. There is also a reasonably close match between the resulting peaks from SHAKE2000 and PEER for

347 soil class $C_{e}$ in Figure 7(c); however, there is a noticeable second peak from SHAKE2000 due to the effects of

348 soil resonance.
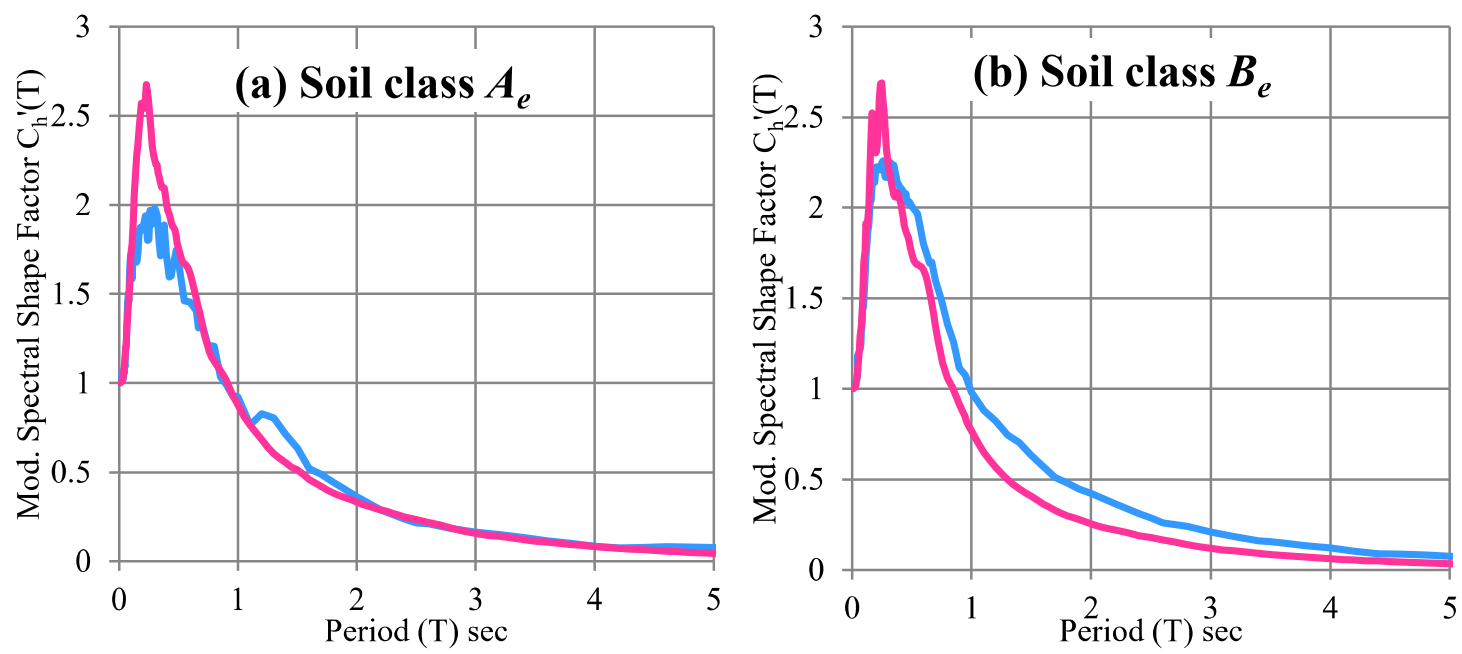

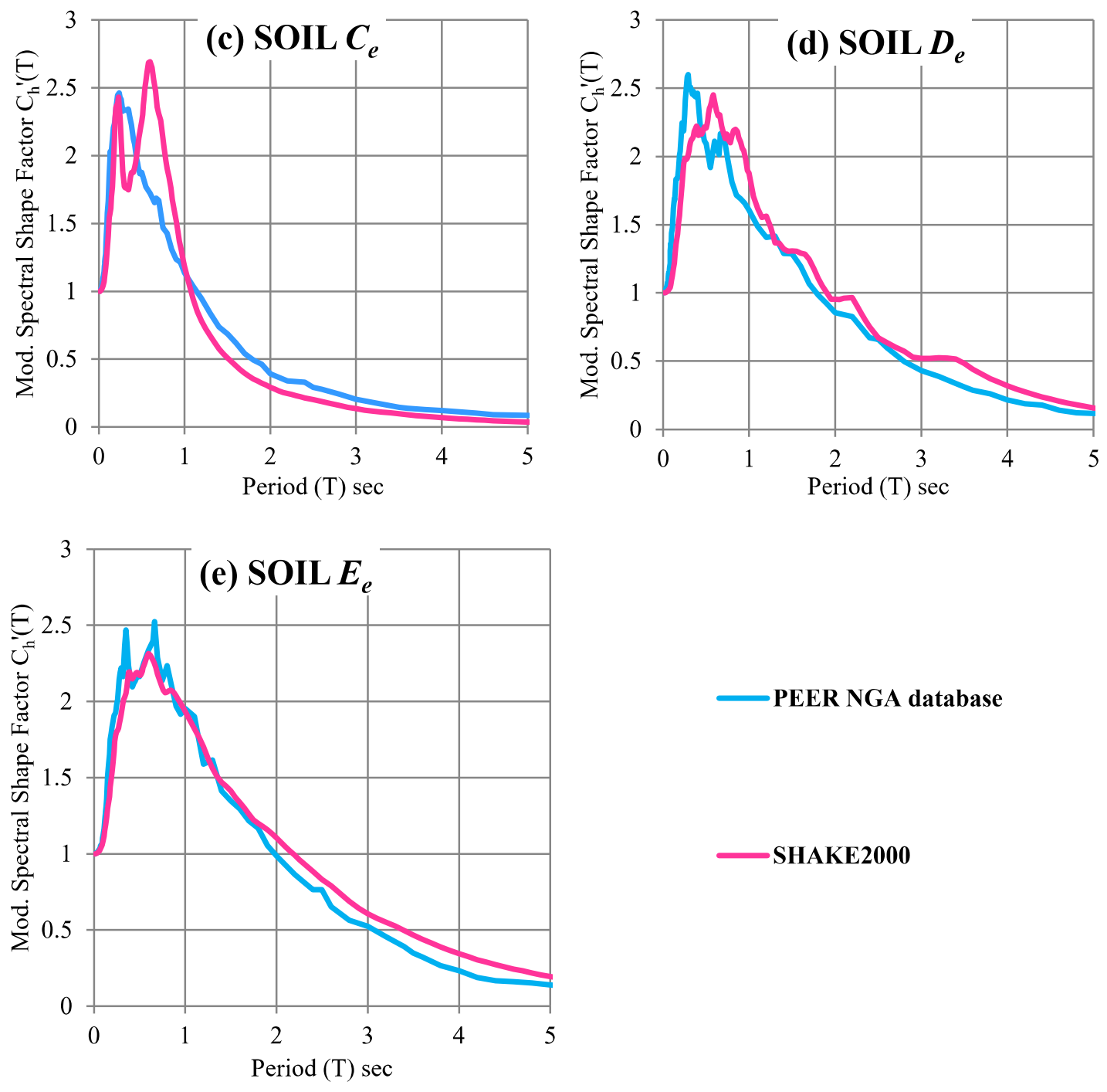

PEER NGA database

SHAKE2000

Figure 7(a-e) Comparison of modified normalised Spectral Shape Factors for PEER and SHAKE2000

\section{Conclusion}

352 An investigation was undertaken to test the validity of the current Spectral Shape Factors used in the low-tomoderate seismic region of Australia. Importantly, strong ground motions available at PEER were used in selecting acceleration-time histories such that the intensity (or $P G A$ ) represented rare to very rare earthquake events in this region. An equivalent linear analysis using SHAKE2000 predicted the acceleration response at the surface for a range of different soil profiles. The strains induced in the soil by the ground motions were generally found to be within the limits suggested by Papaspiliou et al. (2012) and hence the predictions from the equivalent linear analysis used in SHAKE2000 were deemed to be reliable. The results from SHAKE2000 are 
compared to the current spectral shape factors given in AS 1170.4:2007 and recordings on different site conditions from the PEER ground motion database. The main conclusions that can be drawn from the results are as follows:

- The dependency of the soil amplification on the intensity of the earthquake ground motions was only observed for soil classes $C_{e}, D_{e}$ and $E_{e}$.

- Importantly, the influence of site resonance resulted in higher spectral shape factor results for soil class $B_{e}$ and $C_{e}$ at periods close the site period than the factors stipulated in the current AS 1170.4:2007. Resonance effects would be expected to be more pronounced and at higher periods for class $B_{e}$ if the profiles were modelled using a $V_{s 30}$ of $360 \mathrm{~m} / \mathrm{s}$. Future studies should investigate whether larger resonance does occur and also scrutinise the validity of such a low shear wave velocity in representing rock sites.

- The Spectral Shape Factors for $B_{e}$ were considerably higher in the short period range relative to the softer soil of class $E_{e}$.

- For each of the different soil classes the median results for a normalised spectral shape factor, $C_{h}{ }^{\prime}(T)$, correlated well with the results from unscaled records from the PEER database.

This preliminary study has indicated some discrepancies between the results and the current AS 1170.4:2007 spectral shape factors. The results from the deep, sand soil sites, indicate a large (de)amplification of the low period spectral acceleration. This means that low-rise buildings on sandy sites may experience much lower levels of seismic loading than what is currently predicted by conventional earthquake standards. These results indicate that a low-to-moderate intensity earthquake event can cause a large amplification of the structural acceleration response on rock sites and cause damaging effects on stiff structures.

The spectral response from the clay sites analysed here indicates the potential for larger amplification than for sand sites. Therefore, further studies are necessary before amplification factors can be defined with confidence, including investigations with realistic site profiles using borehole records or other methods. However, the general trend of deamplification with increasing seismic intensity was observed for all of the sand and clay sites analysed here.

Spectral shape factors dependent on a seismic intensity factor should be considered for future revisions of the AS 1170.4:2007. This is particularly important if future revisions of the seismic code for the low-to-moderate seismic region involve moving from a consideration of a 500-year design return period design level event to a 
2500-year return period one. An extension of the research presented here is currently being undertaken at the University of Melbourne using similar techniques to those used in this study, but with a wider scope of soil profiles, materials and material properties, and with a focus on displacement response spectra.

\section{Acknowledgements}

The support of the Commonwealth of Australia through the Bushfire and Natural Hazards Cooperative Research Centre program is acknowledged.

\section{References}

Anbazhagan, P., Sheikh, M., \& Parihar, A. (2013). Influence of Rock Depth on Seismic Site Classification for Shallow Bedrock Regions. Natural Hazards Review, 14(2), 108-121. doi: 10.1061/(asce)nh.1527-6996.0000088

Asten, M., Lam, N., Venkatesan, S., Rutter, H. K., \& Wilson, C. J. N. (2005). The importance of shear wave velocity information of a soil site. Paper presented at the Australian Earthquake Engineering Society 2005 Conference, Albury, NSW.

Beresnev, I. A., \& Wen, K.-L. (1996). Nonlinear soil response-A reality? Bulletin of the Seismological Society of America, 86(6), 1964-1978.

Bolisetti, C., Whittaker, A. S., Mason, H. B., Almufti, I., \& Willford, M. (2014). Equivalent linear and nonlinear site response analysis for design and risk assessment of safety-related nuclear structures. Nuclear Engineering and Design, 275, 107-121. doi: http://dx.doi.org/10.1016/j.nucengdes.2014.04.033

Borcherdt, R. D. (1994). Estimates of site-dependent response spectra for design (methodology and justification). Earthquake Spectra, 10(4), 617-653

Bradley, B. A., \& Cubrinovski, M. (2011). Near-source strong ground motions observed in the 22 February 2011 Christchurch earthquake. Seismological Research Letters, 82(6), 853-865.

Brown, A., \& Gibson, G. (2004). A multi-tiered earthquake hazard model for Australia. Tectonophysics, 390(14), 25-43.

Building Seismic Safety Council. (2009). National Earthquake Hazards Reduction Program (NEHRP) recommended seismic provisions for new buildings and other structures (FEMA P-750), 2009 edition. In N. I. o. B. S. Building Seismic Safety Council (Ed.). Washington D.C.

Chandler, A., Pappin, J., \& Coburn, A. (1991). Vulnerability and seismic risk assessment of buildings following the 1989 Newcastle, Australia earthquake. Bulletin of the New Zealand National Society for Earthquake Engineering, 24(2), 116-138.

Chatterjee, K., Choudhury, D., \& Poulos, H. G. (2015). Seismic analysis of laterally loaded pile under influence of vertical loading using finite element method. Computers and Geotechnics, 67, 172-186. doi:http://dx.doi.org/10.1016/j.compgeo.2015.03.004

Crouse, C. B., \& McGuire, J. W. (1996). Site Response Studies for Purpose of Revising NEHRP Seismic Provisions. Earthquake Spectra, 12(3), 407-439. doi: doi:10.1193/1.1585891

Dhakal, R. P., Lin, S. L., Loye, A. K., \& Evans, S. J. (2013). Seismic design spectra for different soil classes. Bulletin of the NZ Society of Earthquake Engineering, 46(2), 79-87.

Eurocode 8. (2004). Design of structures for earthquake resistance. Part 1: general rules, seismic actions and rules for buildings. In E. S. E. 1998-1:2004 (Ed.). Brussels, Belgium, 2004: Comit' e Europ'een de Normalisation. 
Goldsworthy, H. M. (2012). Lessons on building design from the 22 February 2011 Christchurch earthquake. Australian Journal of Structural Engineering, 13(2), 159.

Groholski, D. R., Hashash, Y. M. A., Kim, B., Musgrove, M., Harmon, J., \& Stewart, J. P. (2016). Simplified Model for Small-Strain Nonlinearity and Strength in 1D Seismic Site Response Analysis. Journal of Geotechnical and Geoenvironmental Engineering, 142(9), 04016042. doi: doi:10.1061/(ASCE)GT.19435606.0001496

Hashash, Y. M. A., Dashti, S., Romero, M. I., Ghayoomi, M., \& Musgrove, M. (2015). Evaluation of 1-D seismic site response modeling of sand using centrifuge experiments. Soil Dynamics and Earthquake Engineering, 78, 19-31. doi: http://dx.doi.org/10.1016/j.soildyn.2015.07.003

Hashash, Y. M. A., Musgrove, M. I., Harmon, J. A., Groholski, D. R., Phillips, C. A., \& Park, D. (2016). DEEPSOIL 6.1, User Manual: University of Illinois, Urbana, IL, USA.

Hoult, R. D., Lumantarna, E., \& Goldsworthy, H. M. (2013). Ground Motion Modelling and Response Spectra for Australian Earthquakes. Paper presented at the Australian Earthquake Engineering Society 2013 Conference, Hobart, Tasmania.

Hoult, R. D., Amirsardari, A., Sandiford, D., Lumantarna, E., Goldsworthy, H. M., Gibson, G., \& Asten, M. (2014). The 2012 Moe Earthquake and Earthquake Attenuation in South Eastern Australia. Paper presented at the Australian Earthquake Engineering Society 2014 Conference, Lorne, Victoria.

ICBO. (1994). International Council of Building Officials, Uniform Building Code 1994. Whittier, CA.

ICBO. (1997). International Council of Building Officials, Uniform Building Code 1997. Whittier, CA.

ICC. (2000). Intenation Building Code (IBC). Birmingham, AL, IBC.

ICC. (2009). Intenation Building Code (IBC). Birmingham, AL, IBC.

Jakka, R. S., Roy, N., \& Wason, H. R. (2014). Implications of surface wave data measurement uncertainty on seismic ground response analysis. Soil Dynamics and Earthquake Engineering, 61-62, 239-245. doi:http://dx.doi.org/10.1016/j.soildyn.2014.02.004

Jones, T. D., Neville, M. J., Scott, G., \& Sinadinovski, C. (1996). Earthquake Microzonation and the Developement of the Australian Earthquake Loading Standard. Paper presented at the Paper presented at the Proceedings of the 1996 Australian earthquake Engineering Society Conference, Adelaide.

Kamatchi, P., Rajasankar, J., Iyer, N. R., Lakshmanan, N., Ramana, G. V., \& Nagpal, A. K. (2010). Effect of depth of soil stratum on performance of buildings for site-specific earthquakes. Soil Dynamics and Earthquake Engineering, 30(8), 647-661. doi:http://dx.doi.org/10.1016/j.soildyn.2010.02.007

Lam, N., \& Wilson, J. (1999). Estimation of the site natural period from a borehole record. Australian Journal of Structural Engineering, 1(3), 179-200.

Lam, N. T. K., \& Wilson, J. L. (2008). The new response spectrum model for Australia. Special Issue: Earthquake Engineering in the Low and Moderate Seismic Regions of Southeast Asia and Australia, 6-24.

Leonard, M. (2008). One Hundred Years of Earthquake Recording in Australia. Bulletin of the Seismological Society of America, 98(3), 1458-1470. doi: 10.1785/0120050193

Lumantarna, E., Wilson, J. L., \& Lam, N. T. K. (2012). Bi-linear displacement response spectrum model for engineering applications in low and moderate seismicity regions. Soil Dynamics and Earthquake Engineering, 43, 85-96. doi: http://dx.doi.org/10.1016/j.soildyn.2012.07.006

Martin, G. R., \& Dobry, R. (1994). Earthquake site response and seismic code provisions. NCEER Bulletin, $8(4), 1-6$.

Matasovic, N. (1993). Seismic response of composite horizontally-layered soil deposits. University of California, Los Angeles. 
McPherson, A., \& Hall, L. (2013). Site Classification for Earthquake Hazard and Risk Assessment in Australia. Bulletin of the Seismological Society of America, 103(2A), 1085-1102. doi:10.1785/0120120142

Ordonez, G. A. (2013). SHAKE2000 (Version 9.99.2 - July 2013). Retrieved from http://www.geomotions.com

Papaspiliou, M., Kontoe, S., \& Bommer, J. J. (2012). An exploration of incorporating site response into PSHApart II: Sensitivity of hazard estimates to site response approaches. Soil Dynamics and Earthquake Engineering, 316. doi: 10.1016/j.soildyn.2012.05.001

PEER. (2010). User Manual for the PEER Ground Motion Database Web Application (Version Beta Version October 1, 2010).

PEER. (2013). Pacific Earthquake Engineering Research (PEER) Center Ground Motion Database, from http://peer.berkeley.edu/peer_ground_motion_database/.

Schnabel, P. B. (1973). Effects of local geology and distance from source on earthquake ground motions. (Ph.D.), University of California, Berkeley, California.

Schnabel, P. B., Lysmer, J., \& Seed, H. B. (1972). SHAKE: A Computer Program for Earthquake Response Analysis of Horizontally Layered Sites, EERC 72-12. College of Eng. University of California Berkeley, California.

Seed, H. B., \& Idriss, I. M. (1970). Soil moduli and damping factors for dynamic response analyses (Vol. Report No. EERC 70-10): University of California, Berkekley, December.

Seed, H. B., \& Idriss, I. M. (1982). Ground motions and soil liquefaction during earthquakes (Vol. 5): Earthquake Engineering Research Institute.

So, M., Thompson, T., \& Mote, T. (2015). Site-Specific Response Analysis in Australia and Comparison with AS1170. 4 and Geoscience Australia 2012 Seismic Hazard Maps. Paper presented at the 6th International Conference on Earthquake Geotechnical Engineering, Christchurch, New Zealand.

Standards Australia. (2007). AS 1170.4-2007: Structural design actions, Part 4: Earthquake actions in Australia.

Standards Association NZ. (2004). NZS 1170.5:2004," Structural Design Actions and Commentary, Part 5, Earthquake Actions". Wellington, New Zealand.

Vucetic, M., \& Dobry, R. (1991). Effect of Soil Plasticity on Cyclic Response. Journal of Geotechnical Engineering, 117(1), 89-107. doi: doi:10.1061/(ASCE)0733-9410(1991)117:1(89)

Walker, G. (2011). Comparison of the Impacts of Cyclone Tracy and the Newcastle Earthquake on the Australian Building and Insurance Industries.

Walling, M., Silva, W., \& Abrahamson, N. (2008). Nonlinear Site Amplification Factors for Constraining the NGA Models. Earthquake Spectra, 24(1), 243-255. doi: doi:10.1193/1.2934350

Wilson, J., Lam, N., \& Pham, L. (2008). Development of the new Australian earthquake loading standard: EJSE International Ltd 2008.

\section{Appendix}

\begin{tabular}{|c|c|c|c|c|c|c|c|}
\hline NGA\# & $\mathrm{M}$ & Mechanism & $R_{j b}(\mathrm{~km})$ & $V_{s 30}(\mathrm{~m} / \mathrm{s})$ & Scale $(\mathrm{Z}=0.1 \mathrm{~g})$ & Scale $(\mathrm{Z}=0.2 \mathrm{~g})$ & Scale $(\mathrm{Z}=0.3 \mathrm{~g})$ \\
\hline 1011 & 6.69 & Reverse & 15.1 & 1223 & 0.9 & 1.7 & 2.6 \\
\hline
\end{tabular}




\begin{tabular}{|c|c|c|c|c|c|c|c|}
\hline 769 & 6.93 & Reverse-Oblique & 17.9 & 663 & 0.6 & 1.1 & 1.7 \\
\hline 957 & 6.69 & Reverse & 15.9 & 822 & 0.9 & 1.7 & 2.6 \\
\hline 3171 & 6.2 & Reverse & 62.9 & 668 & 2.7 & 5.4 & 8.1 \\
\hline 1091 & 6.69 & Reverse & 23.1 & 996 & 0.7 & 1.4 & 2.0 \\
\hline 443 & 5.1 & Normal & 21.0 & 660 & 6.0 & 12.0 & 18.0 \\
\hline 283 & 6.9 & Normal & 52.9 & 1000 & 3.0 & 5.9 & 8.9 \\
\hline 3507 & 6.3 & Reverse & 22.7 & 664 & 0.7 & 1.3 & 2.0 \\
\hline 2966 & 6.2 & Reverse & 91.2 & 603 & 2.7 & 5.3 & 8.0 \\
\hline 3251 & 6.2 & Reverse & 84.7 & 845 & 2.9 & 5.7 & 8.6 \\
\hline 2952 & 6.2 & Reverse & 62.8 & 680 & 2.1 & 4.2 & 6.2 \\
\hline 133 & 5.91 & Reverse & 14.4 & 660 & 1.3 & 2.6 & 3.9 \\
\hline 3472 & 6.3 & Reverse & 23.8 & 615 & 0.9 & 1.7 & 2.6 \\
\hline 2687 & 6.2 & Reverse & 93.2 & 845 & 12.7 & 25.3 & 38.0 \\
\hline 3202 & 6.2 & Reverse & 49.7 & 714 & 2.1 & 4.1 & 6.2 \\
\hline 1027 & 6.69 & Reverse & 36.9 & 685 & 1.3 & 2.6 & 3.8 \\
\hline 59 & 6.61 & Reverse & 89.4 & 814 & 5.5 & 10.9 & 16.4 \\
\hline 3025 & 6.2 & Reverse & 39.9 & 643 & 2.4 & 4.8 & 7.2 \\
\hline 1029 & 6.69 & Reverse & 37.0 & 685 & 1.1 & 2.3 & 3.4 \\
\hline 303 & 6.2 & Normal & 20.4 & 1000 & 1.7 & 3.4 & 5.0 \\
\hline 3531 & 6.3 & Reverse & 84.5 & 646 & 6.3 & 12.5 & 18.8 \\
\hline
\end{tabular}




\begin{tabular}{|c|c|c|c|c|c|c|c|}
2367 & 5.9 & Reverse & 59.1 & 705 & 5.3 & 10.6 & 15.8 \\
\hline 994 & 6.69 & Reverse & 21.2 & 1016 & 0.5 & 1.1 & 1.6 \\
\hline 2245 & 5.9 & Reverse & 53.9 & 643 & 10.9 & 21.8 & 32.8 \\
\hline 63 & 6.61 & Reverse & 25.6 & 685 & 2.0 & 4.0 & 6.0 \\
\hline 1033 & 6.69 & Reverse & 46.3 & 822 & 1.5 & 3.1 & 4.6 \\
\hline 2627 & 6.2 & Reverse & 13.0 & 615 & 0.4 & 0.8 & 1.2 \\
\hline 2601 & 6.2 & Reverse & 76.9 & 705 & 11.6 & 23.2 & 34.7 \\
\hline 3249 & 6.2 & Reverse & 66.5 & 728 & 4.0 & 8.1 & 12.1 \\
\hline
\end{tabular}

506 